Article

\title{
Modification of Surface Hydrophobicity of PLA/PE and ABS/PE Polymer Blends by ICP Etching and $\mathrm{CF}_{\mathrm{x}}$ Coating
}

\author{
Vedrana Lovinčić Milovanović ${ }^{1, *}$, Cédric Guyon ${ }^{2}$, Ivana Grčić ${ }^{3}$, Michael Tatoulian ${ }^{2}$ \\ and Domagoj Vrsaljko $4, *$ (D) \\ 1 MAXICON Inc., Kružna 22, 10000 Zagreb, Croatia \\ 2 Chimie ParisTech, PSL University, CNRS, Institut de Recherche de Chimie Paris, 75005 Paris, France; \\ cedric.guyon@chimieparistech.psl.eu (C.G.); michael.tatoulian@chimie-paristech.fr (M.T.) \\ 3 Faculty of Geotechnical Engineering, University of Zagreb, 42000 Varaždin, Croatia; ivana.grcic@gfv.hr \\ 4 Faculty of Chemical Engineering and Technology, University of Zagreb, 10000 Zagreb, Croatia \\ * Correspondence: vedrana.lovincic@maxicon.hr (V.L.M.); dvrsal@fkit.hr (D.V.)
}

Received: 21 October 2020; Accepted: 2 December 2020; Published: 7 December 2020

\begin{abstract}
The flow regime inside the channel of 3D printed microreactors is defined by the surface properties of the channel walls. Polylactide (PLA) and acrylonitrile/butadiene/styrene (ABS) are two polymers that are the most common in additive manufacturing using fused filament fabrication, commonly known as "3D printing". With the aim of developing new materials for the 3D printing of microreactors whose channel surface hydrophobicity could be modified, PLA and ABS were blended with cheaper and widely used polymers-high-density polyethylene (PE-HD) and low-density polyethylene (PE-LD). Polymer blend surfaces were treated with inductively coupled plasma (ICP) and coated by fluorocarbon-based material $\left(\mathrm{CF}_{\mathrm{x}}\right)$ plasma deposition treatment in order to modify surface hydrophobicity. It has been shown that the modification of surface morphology of PLA polymer blends can be achieved by ICP etching and $\mathrm{CF}_{\mathrm{x}}$ coating, while this was not possible for ABS polymer blends under the conducted treatment conditions. The treated surface of PLA/PE-HD $90 / 10$ showed a contact angle of $121.6^{\circ}$ which is $36^{\circ}$ higher than the contact angle measured on the untreated surface. Surfaces that have achieved contact angles higher than $120^{\circ}$ have an "island like" surface morphology. Samples with higher "islands" showed higher contact angles, that confirmed that the hydrophobicity also depends on the height of the "islands". Furthermore, it has been found that etching time significantly impacts the contact angle values and surface morphology of the PLA polymer blends, while the $\mathrm{CF}_{\mathrm{x}}$ coating time does not have significant impact on the surface properties.
\end{abstract}

Keywords: acrylonitrile/butadiene/styrene; microreactors; polylactide; 3D printing; surface hydrophobicity

\section{Introduction}

Nowadays, superhydrophobicity of surfaces is a desirable property in many products and technologically important materials. Reduction in water resistance on ships and surface protection of equipment in contact with water are unthinkable without hydrophobic coatings. Hydrophobic impregnation is the basic protection method of concrete bridges, silos, buildings and walls and it is applied in order to prevent the penetration of water into the concrete structure. Prescription eyeglasses with a hydrophobic layer to prevent the retention of raindrops, waterproof textiles, facade paints and nano-polymer coatings on cars for reduced adhesion and self-cleaning during rain, are examples of today's wide-ranging applications of surface superhydrophobicity properties in everyday life. The inspiration for the development of such products comes from nature. One of the most famous examples of a plant with superhydrophobic surface properties is the lotus flower (lat. Nelumbo nucifera). 
The term superhydrophobicity is used for hydrophobic surfaces where the contact angle with water is greater than $150^{\circ}$. The contact angle (usually identified as $\theta$ ) is an angle between the solid surface and the tangent placed on the droplet from the point where the three intermediate surfaces meet (solid-liquid, liquid-vapor and solid-vapor), as shown in Figure 1.

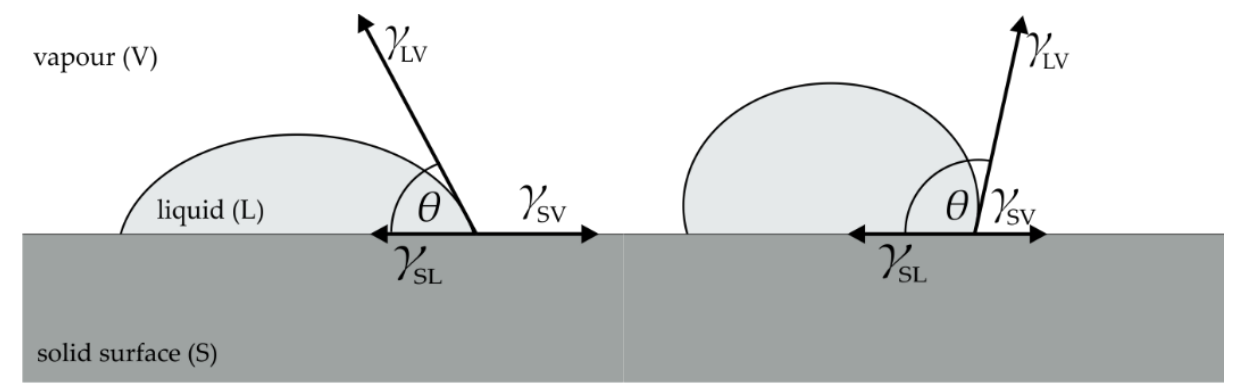

(a)

(b)

Figure 1. Contact angles of liquids on (a) non-hydrophobic and (b) hydrophobic surface.

A flat solid surface contact angle can be derived from Young's Equation (1) as $\cos \theta(2)$ :

$$
\begin{gathered}
\gamma_{\mathrm{SL}}+\gamma_{\mathrm{LV}} \cos \theta=\gamma_{\mathrm{SV}} \\
\cos \theta=\frac{\gamma_{\mathrm{SV}}-\gamma_{\mathrm{SL}}}{\gamma_{\mathrm{LV}}}
\end{gathered}
$$

where $\gamma_{\mathrm{SL}}$ is surface tension (free surface energy) that occurs at the solid-liquid interface, $\gamma_{\mathrm{LV}}$ is the surface tension (free surface energy) at the liquid-vapor interface and $\gamma_{\mathrm{SV}}$ is the surface tension (free surface energy) at the solid-vapor interface. If the contact angle is less than $90^{\circ}$, the liquid will spill and cover the solid surface. It is considered as a good wetting property and also a hydrophilic property of the surface when the liquid is water. If the contact angle is greater than $90^{\circ}$, the liquid remains on the limited surface in the form of a droplet. It is considered as poorly wetting or not wetting property, as well as a hydrophobic property of the surface when the liquid is water.

However, Young's equation is applicable only to a smooth and flat surfaces. When a droplet comes in contact with a rough surface, the droplet can completely cover the surface, thus increasing the interface that is in contact with the liquid, as described by Wenzel [1]. It can also cross over rough parts of the surface and leave the interfaces of the solid-liquid and liquid-vapour beneath, as suggested by Cassie and Baxter [2,3]. Figure 2 shows the behavior of a liquid on a smooth surface and the proposed models of behavior on a rough surface.

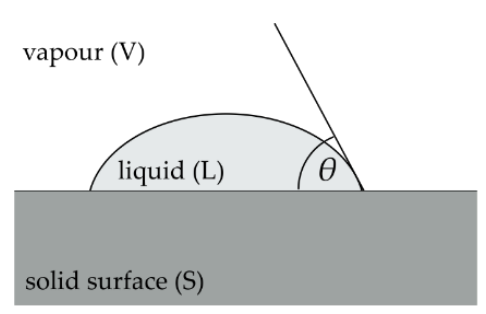

Young

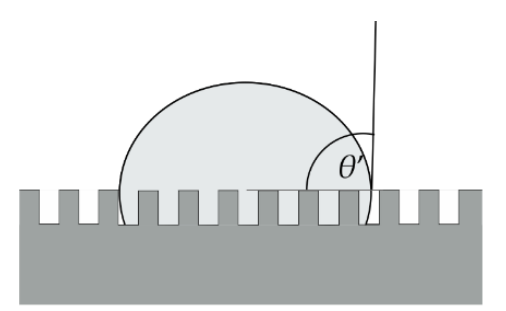

Wenzel

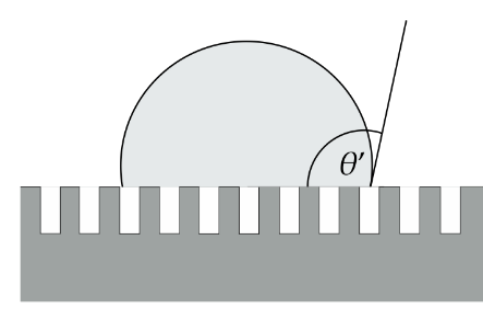

Cassie-Baxter

Figure 2. Behavior of liquid on smooth and rough surface.

When the liquid completely covers the rough surface, Wenzel [1] proposed a modification of Young's equation to calculate the contact angle $\theta^{\prime}$ taking into account the surface roughness factor, $r$ (3).

$$
\cos \theta^{\prime}=\frac{r\left(\gamma_{\mathrm{SV}}-\gamma_{\mathrm{SL}}\right)}{\gamma_{\mathrm{LV}}}=r \cos \theta
$$


The surface roughness factor represents the ratio of the real area of the rough surface and the geometric projection of the same surface. $\theta$ represents the contact angle at the smooth and flat surface. According to Wenzel's rough surface model, roughness enhances the surface property towards stronger hydrophilicity of the hydrophilic surface or towards stronger hydrophobicity of hydrophobic surface [4].

For the other model, when the droplet crosses over rough parts of the surface and leaves the trapped vapour beneath, Cassie and Baxter [2,3] suggested a modification of Young's equation for calculating the contact angle $\theta^{\prime}$, taking into account the proportion of the solid surface in contact with the liquid, $f_{S}(4)$ :

$$
\cos \theta^{\prime}=\frac{f_{\mathrm{S}}\left(\gamma_{\mathrm{SV}}-\gamma_{\mathrm{SL}}\right)}{\gamma_{\mathrm{LV}}}-\left(1-f_{\mathrm{S}}\right)=f_{\mathrm{S}} \cos \theta-\left(1-f_{\mathrm{S}}\right)
$$

where $\left(1-f_{\mathrm{S}}\right)$ represents the portion of liquid in contact with vapour and $\theta$ represents the contact angle at the smooth and flat surface. Although the roughness factor $r$ is not directly present in the Cassie-Baxter Equation (4), the Cassie-Baxter model assumes that the surface is topographically complex and the surface is considered rough.

Superhydrophobic surfaces $\left(\theta\right.$ greater than $150^{\circ}$ ) are extremely difficult to wet and they show a self-cleaning effect [5]. It has been shown that the self-cleaning effect develops on surfaces that have low surface free energy, high water contact angle and high surface roughness, i.e., complex surface morphology [5].

When choosing materials for production of microreactors by 3D printing, it is important to take into account that the flow in microchannels depends on the interactions of molecules with the solid surface. Therefore, surface hydrophobicity, and particularly superhydrophobicity, is a desirable surface property of the microreactor.

Polylactide (PLA) and acrylonitrile/butadiene/styrene (ABS) — the most commonly used polymers for 3D printing-do not show surface superhydrophobicity. Modification of the surface properties of polymers can be achieved by blending two different polymers and by treatment of the polymer blends [6-14]. To achieve superhydrophobicity of the surface on different metal and polymer surfaces, various treatments can be applied, such as sol-gel reactions [15-17], electrochemical deposition [18-20], layer-by-layer deposition [21,22] and spin-coating [23]. Each of these methods has its advantages and disadvantages and one of the most promising techniques for the development of superhydrophobic surfaces is plasma etching [24-26]. Plasma etching is a dry and precise technique. It is a selective technique where usually one phase or compound reacts more quickly with the plasma, so the etching rate is different at different places on the surface [25].

Improvement of the hydrophobicity of PLA polymer blends has already been investigated and it has been shown that a change in the surface of the polymer blend and specific surface roughness can be achieved by plasma etching techniques and surface post-treatment $[27,28]$. According to the available literature, no research of this type has been performed with ABS polymer blends. The effects of etching on the ABS surface were investigated back in 1968 [29], but the etching was carried out as a wet process with the mixture of chromium-sulfuric acid. Research has shown that the chemical acts selectively on rubber particles (polybutadiene), while the matrix remains largely unchanged. Additionally, it has been shown that larger rubber particles are more susceptible to etching, while small particles remain almost unchanged [29]. The research on the possibilities of etching the polymer blends with ABS was carried out on polymer blend of thermoplastic polyurethane elastomer (TPU) and ABS [30]. The etching was also carried out as a wet process where methyl ethyl ketone (MEK) was used for surface treatment. Research has shown that the duration of etching is very important. SEM micrographs of the sample have shown that after $2 \mathrm{~h}$ of etching, the morphology of the surface is very similar to the untreated sample, after $3 \mathrm{~h}$ of etching cavities are clearly visible indicating the morphology of the dispersed ABS phase in the TPU matrix, while after $4 \mathrm{~h}$ the sample is unsuitable for SEM so determination of morphology could not be obtained. 
The flow regime inside the channel of every microreactor is defined by the surface properties of the channel walls. With the aim of developing new materials for 3D printing of microreactors, whose channel surface hydrophobicity could be modified, PLA and ABS based materials are studied. More specifically, this research investigated possibility of surface hydrophobicity modification of PLA/low-density polyethylene (PE-LD), PLA/high-density polyethylene (PE-HD), ABS/PE-LD and ABS/PE-HD polymer blends prepared in 95/10, 90/10 and 80/20 weight ratios. Polymer blend surfaces were treated with inductively coupled plasma (ICP) and coated with fluorocarbon-based material $\left(\mathrm{CF}_{\mathrm{x}}\right)$ plasma deposition treatment. Polymer weight ratios were selected based on previous research where significant modification of hydrophobicity was achieved on PLA/PE-LD polymer blend exactly in 90/10 ratio [28]. "Island like" morphology was created on the surface and increased hydrophobicity was obtained.

\section{Materials and Methods}

Polymers used for the investigation were: polylactide (PLA), Ingeo ${ }^{\mathrm{TM}} 4043 \mathrm{D}$ (NatureWorks LLC, Blair, NE, USA), designed for injection molding applications; acrylonitrile/butadiene/styrene (ABS), Magnum ${ }^{\mathrm{TM}} 3504$ (Trinseo Europe $\mathrm{GmbH}$, Samstagern, Switzerland); low-density polyethylene (PE-LD), DOW ${ }^{\mathrm{TM}}$ LDPE 780E (The Dow Chemical Company, Horgen, Switzerland) and high-density polyethylene (PE-HD), 2004 TN 52 (Total Petrochemicals, Saint-Avold, France).

Polymer blends were mechanically mixed using twin-screw extruder (Rondol $21 \mathrm{~mm}$ LAB TWIN) (Rondol Technology Ltd., Stoke on Trent, United Kingdom) at a rotational frequency of $50 \mathrm{rpm}$. Polymer blends with PLA were prepared at a temperature of $160^{\circ} \mathrm{C}$ while the ABS polymer blends were prepared at a temperature of $180{ }^{\circ} \mathrm{C}$ due to the higher melting temperature of ABS compared to PLA. Polymer components were mixed in a vessel and added in the extruder. Extruded blends were cut up in small pieces and $1 \mathrm{~mm}$ thick sheets were formed by hot pressing. Hot pressing was performed with $11 \mathrm{MPa}$ pressure, at $190{ }^{\circ} \mathrm{C}$ with preheating time 3-4 min and heating for $5 \mathrm{~min}$ on a Dake hydraulic press (Dake, Grand Haven, MI, USA). Fontijne press (Fontijne Presses, Delft, The Netherlands) was used to cool the sheets to the room temperature. Polymer blends were prepared in weight ratios 95/5, 90/10 and 80/20.

In order to increase the hydrophobicity by changing the surface topography of two-component polymer blends, polymer blends and pure polymers were etched using inductively coupled argon plasma (ICP) and treated with a fluorocarbon-based Teflon-like coating $\left(\mathrm{CF}_{\mathrm{x}}\right)$.

ICP etching was conducted in a Hybrid Plasmionique reactor (Plasmionique Inc., Varennes, QC, Canada) under the process conditions: $2.5 \mathrm{kV}, 75 \mathrm{~W}$, different time of processing as shown in Table 1 , $p=5.4 \times 10^{-4}$ Torr $=7.2 \times 10^{-2} \mathrm{~Pa}, p$ (before treatment $)=7 \times 10^{-6}$ Torr $=9.3 \times 10^{-4} \mathrm{~Pa}$.

Table 1. Processing conditions.

\begin{tabular}{ccc}
\hline \multirow{2}{*}{ Batch Label } & \multicolumn{2}{c}{ Time of Processing } \\
\cline { 2 - 3 } & Etching (E) & Teflon-Like $\mathbf{C F}_{\mathbf{x}}$ Coating (T) \\
\hline $\mathrm{E} 0+\mathrm{T} 30$ & - & $30 \mathrm{~min}$ \\
$\mathrm{E} 400+\mathrm{T} 30$ & $400 \mathrm{~s}$ & $30 \mathrm{~min}$ \\
$\mathrm{E} 800+\mathrm{T} 30$ & $800 \mathrm{~s}$ & $30 \mathrm{~min}$ \\
$\mathrm{E} 1600+\mathrm{T} 30$ & $1600 \mathrm{~s}$ & $30 \mathrm{~min}$ \\
$\mathrm{E} 1600+\mathrm{T} 15$ & $1600 \mathrm{~s}$ & $15 \mathrm{~min}$ \\
$\mathrm{E} 1600+\mathrm{T} 60$ & $1600 \mathrm{~s}$ & $60 \mathrm{~min}$ \\
$\mathrm{E} 4000+\mathrm{T} 30$ & $4000 \mathrm{~s}$ & $30 \mathrm{~min}$ \\
\hline
\end{tabular}

$\mathrm{CF}_{\mathrm{x}}$ coating was performed in a FLR300-H Plasmionique PECVD reactor (Plasmionique Inc., Varennes, $\mathrm{QC}$, Canada) under the process conditions: $V\left(\mathrm{CF}_{4}\right)=84 \mathrm{~cm}^{3} \mathrm{~min}^{-1}, V\left(\mathrm{H}_{2}\right)=5 \mathrm{~cm}^{3} \mathrm{~min}^{-1}, 35 \mathrm{~W}$, different time of processing as shown in Table $1, p=260$ mTorr $=35 \mathrm{~Pa}, p$ (before treatment) $=1.7 \times 10^{-6}$ Torr $=$ $2.3 \times 10^{-4} \mathrm{~Pa}$. 
Contact angle of the droplet at the three-phase boundary was measured by sessile drop method at $23^{\circ} \mathrm{C}$ using an OCA 20 goniometer (DataPhysics Instruments, Filderstadt, Germany). Deionized water $\left(\kappa=2.0 \mu \mathrm{S} \mathrm{cm}^{-1}\right)$ with a droplet volume of $3 \mu \mathrm{L}$ was used. Five contact angle measurements were performed on each sample.

Morphology was studied by the scanning electron microscope (SEM) on the surfaces of selected samples. VEGA 3 Tescan scanning electron microscope (Tescan, Brno, Czechia) was used. All the samples were gold sputtered prior to SEM characterization.

Heights of the islands (relative to the surrounding surface) were determined by vertical scanning interferometry (VSI). Wyko NT9100 device (Veeco, Plainview, NY, USA) was used for the research. The height of the island was determined by measuring the height difference between the middle and at the edge of the island. The middle and edge of the "island" were determined visually.

\section{Results and Discussion}

Previous research on PLA/PE-LD and PLA/PE-HD polymer blends, where thermal properties of the selected samples were determined by the differential scanning calorimetry (DSC) and SEM characterization were conducted, has shown that PLA and PE-LD as well as PLA and PE-HD in 90/10 ratio are both immiscible blends, with high crystallization degree and no interaction between dispersed (polyethylene) phase and the matrix (PLA) [31].

The contact angle, as a surface property that indicates the surface hydrophobicity, was determined by the sessile drop method. The measurements were performed on untreated samples and samples treated by etching and coating with $\mathrm{CF}_{\mathrm{x}}$. Obtained results for the polymer blends PLA/PE-LD and PLA/PE-HD are given in Figures 3 and 4. All data can be found in Supplementary Materials-Table S1.

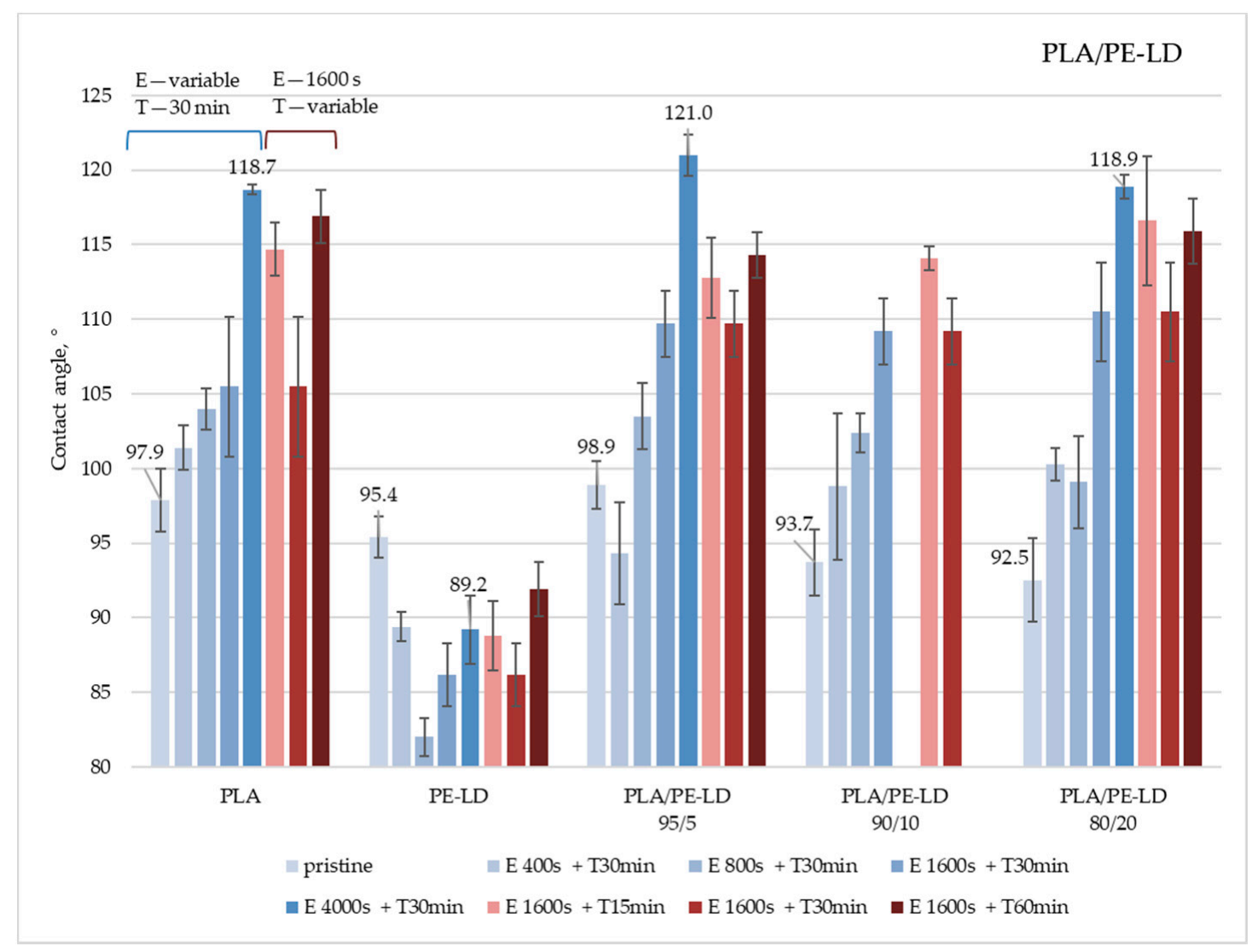

Figure 3. Water contact angles on Polylactide (PLA)/low-density polyethylene (PE-LD) polymer blends treated under different etching and coating conditions (E-etching; $\mathrm{T}-\mathrm{CF}_{\mathrm{X}}$ coating). 


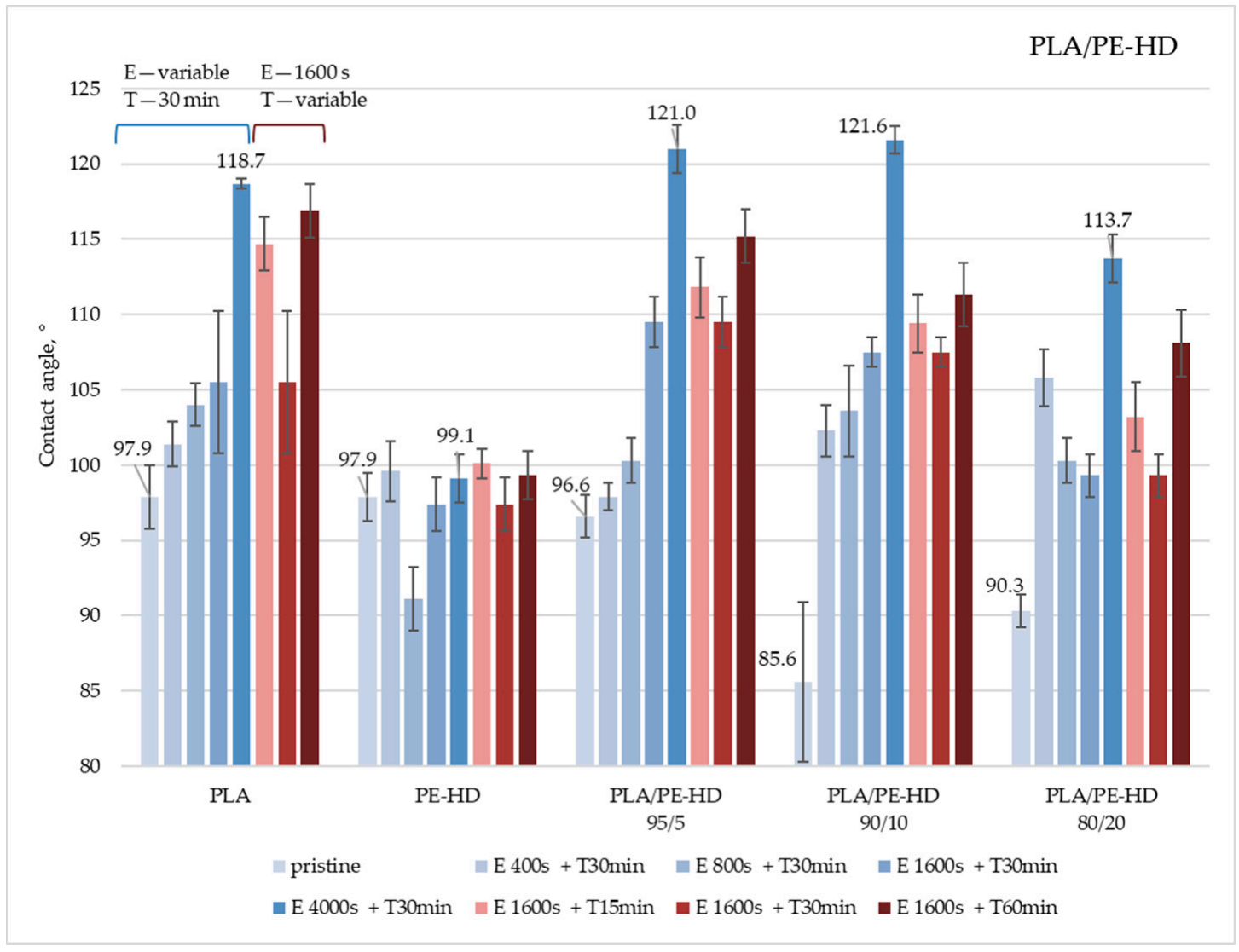

Figure 4. Water contact angles on PLA/high-density polyethylene (PE-HD) polymer blends treated under different etching and coating conditions (E-etching; $\mathrm{T}-\mathrm{CF}_{\mathrm{x}}$ coating).

The obtained results show that hydrophobicity of pure PLA can be increased with ICP etching and $\mathrm{CF}_{\mathrm{x}}$ coating. Unlike the PLA, results for the pure PE-LD sample show that higher contact angle is not achieved after any of the applied treatments. Such results suggest that PE-LD should be less etched than PLA in PLA/PE-LD blends so the "island like" structure could be expected. Results for PLA/PE-LD polymer blends (Figure 3) show that almost all treated samples of PLA/PE-LD polymer blends have a higher water contact angle than the untreated samples, as expected. Additionally, it is important to notice that an increase in processing time, regardless of the applied treatment-etching or $\mathrm{CF}_{\mathrm{X}}$ coating-does not necessarily lead to an increase in the water contact angle. The best results on all PLA/PE-LD samples are achieved by etching for $4000 \mathrm{~s}$ and $\mathrm{CF}_{\mathrm{x}}$ coating for $30 \mathrm{~min}$. The largest modification in hydrophobicity, when comparing contact angles of untreated and treated sample, is achieved on a PLA/PE-LD 95/5 sample treated by etching for $4000 \mathrm{~s}$ and $\mathrm{CF}_{\mathrm{x}}$ coating for $30 \mathrm{~min}$, achieving a contact angle difference of $22.1^{\circ}$. The highest contact angle, $121.0^{\circ}$, is measured on the same sample (PLA/PE-LD 95/5). Even though the trend for all treated PLA/PE-LD samples shows an increase in water contact angle, the PLA/PE-LD 95/5 sample failed to achieve a higher contact angle after etching for $400 \mathrm{~s}$ and $\mathrm{CFx}$ coating for $30 \mathrm{~min}$. Such behavior can be considered as an experimental error.

Similar results were obtained for PE-HD and PLA/PE-HD samples (Figure 4). The highest increase in the contact angle, i.e., increase in the hydrophobicity, in all samples is achieved by etching for $4000 \mathrm{~s}$ and $\mathrm{CF}_{\mathrm{x}}$ coating for $30 \mathrm{~min}$. The largest modification in hydrophobicity, comparing the contact angle for untreated and treated samples, is achieved on a PLA/PE-HD 90/10 sample treated by etching for $4000 \mathrm{~s}$ and $\mathrm{CF}_{\mathrm{x}}$ coating for $30 \mathrm{~min}$, achieving a contact angle difference of $36.0^{\circ}$. The highest contact angle, $121.6^{\circ}$, is measured on the same sample (PLA/PE-HD 90/10). Furthermore, it can be concluded that surfaces coated for $60 \mathrm{~min}$ show the highest contact angle, compared to the surfaces coated for shorter times. 
The obtained results for both PLA/PE-LD and PA/PE-HD polymer blends indicate that surface morphology is modified in a way that PLA is more etched than the PE so the surface is topographically complex and the surface can be considered rough.

These findings are confirmed with the SEM micrographs given in Figures 5 and 6. In our previous research [31], SEM micrographs have shown that domains of PE-LD, as well as PE-HD were dispersed in the PLA matrix and PLA was dispersed in PE matrix when PE amount was higher. These results indicated an immiscibility of the two phases. Blends with dispersed PLA domains in PE matrix have shown the "crater like" structure after the etching, and the $\mathrm{CF}_{\mathrm{x}}$ coating did not change the water contact angle significantly. On the contrary, blends with dispersed PE domains in PLA matrix had shown the "island like" structure after the etching, and the $\mathrm{CF}_{\mathrm{x}}$ coating changed the water contact angle significantly. For this reason, in this research "island like" structures were expected as a result of different etching rates on the different phases.
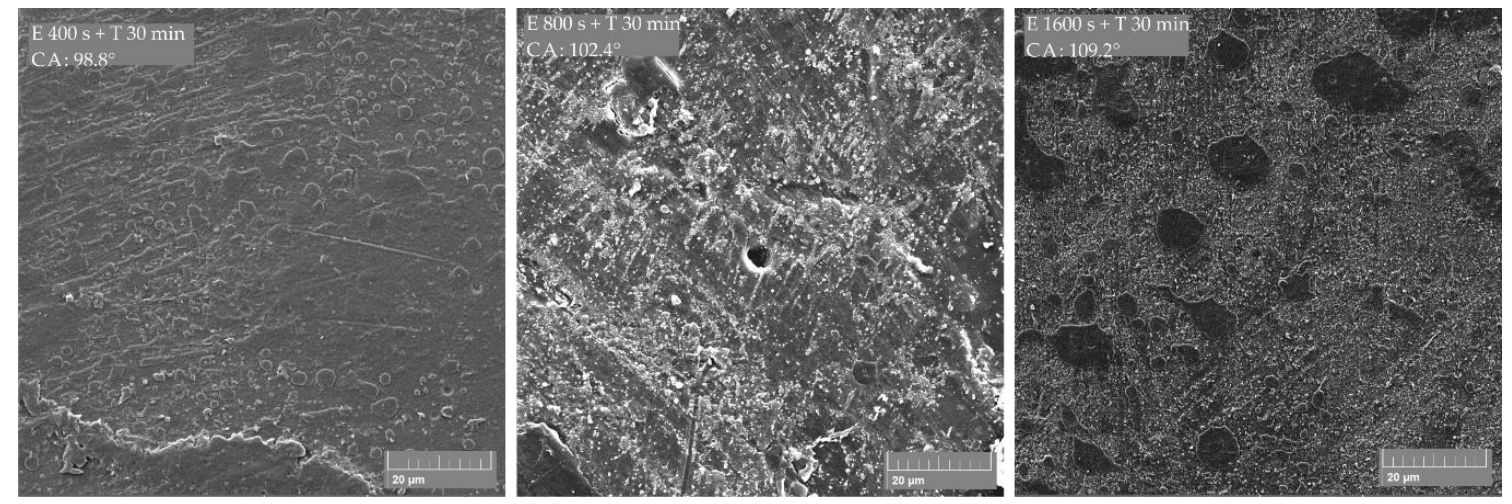

Figure 5. SEM micrographs of PLA/PE-LD 90/10 polymer blend treated by etching $(\mathrm{E})$ and $\mathrm{CF}_{\mathrm{x}}$ coating (T); measured contact angle is indicated as CA.
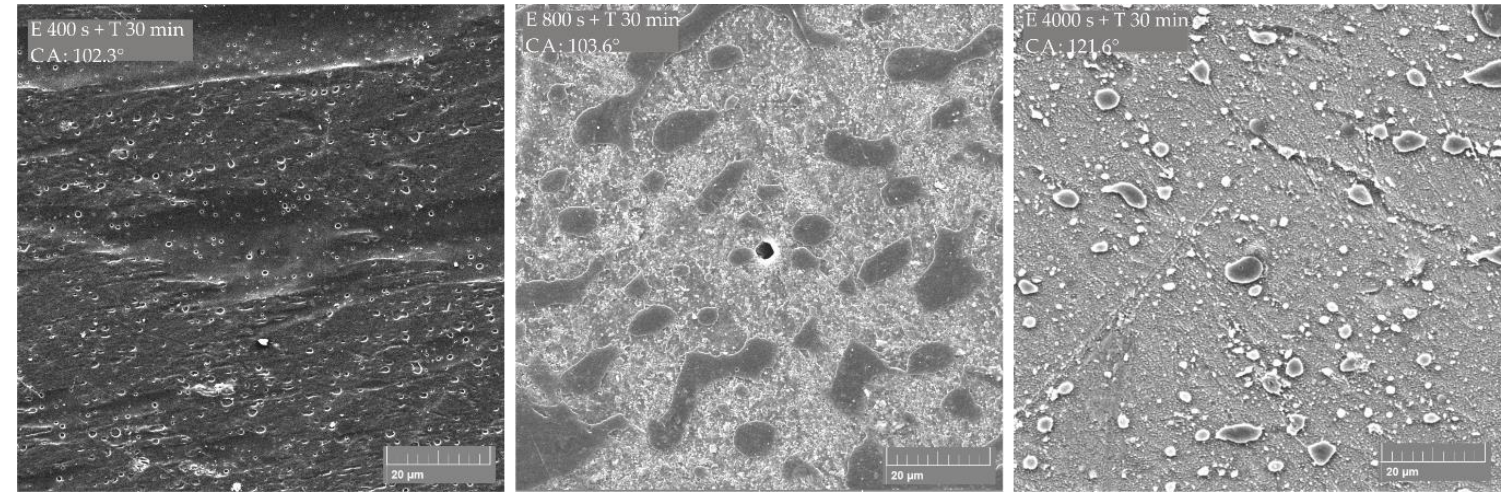

Figure 6. SEM micrographs of PLA/PE-HD 90/10 polymer blend treated by etching $(\mathrm{E})$ and $\mathrm{CF}_{\mathrm{x}}$ coating (T); measured contact angle is indicated as CA.

SEM micrographs of the PLA/PE-LD 90/10 polymer blend (Figure 5) show the formation of an "island like" structure where the matrix (PLA) is more etched and the dispersed domain (PE-LD) is less etched and stands like an island above the matrix level. Such an "island like" structure is produced already with etching for $400 \mathrm{sec}$ and $\mathrm{CF}_{\mathrm{x}}$ coating for $30 \mathrm{~min}$, but it seems that the island does not reach a sufficient height to significantly increase the contact angle. The measured contact angle on the treated surface was $98.8^{\circ}$, which is $5.1^{\circ}$ higher than on the untreated surface. When etched for $1600 \mathrm{~s}$ and $\mathrm{CF}_{\mathrm{x}}$ coated for $30 \mathrm{~min}$, the islands visually appear higher than the surrounding matrix and a higher contact angle $\left(109.2^{\circ}\right)$ is achieved. Island size ranges from $2 \mu \mathrm{m}$ to $20 \mu \mathrm{m}$, and $6 \mu \mathrm{m}$ sized islands are the most common. 
SEM micrographs of the PLA/PE-HD 90/10 polymer blend (Figure 6) show similar surface morphology like the PLA/PE-LD 90/10 blend. The "island like" structure is gained after etching for $800 \mathrm{~s}$ and $\mathrm{CF}_{\mathrm{x}}$ coating for $30 \mathrm{~min}$ and the measured contact angle is $103.6^{\circ}$. The highest contact angle achieved in this study is $121.6^{\circ}$. It is achieved on a surface with the $4 \mu \mathrm{m}$ to $8 \mu \mathrm{m}$ wide islands, and the $6 \mu \mathrm{m}$ wide islands are the most common. The distance between islands ranges from $10 \mu \mathrm{m}$ to $20 \mu \mathrm{m}$. This surface structure is achieved by etching for $4000 \mathrm{~s}$ and $\mathrm{CF}_{\mathrm{x}}$ coating for $30 \mathrm{~min}$.

In order to compare the island heights determined by SEM, a series of untreated and treated surfaces of the PLA/PE-HD 80/20 polymer blend were scanned by vertical scanning interferometry (VSI). This technique is based on white light interferometry, where shallow depths of surface are in focus so the surface must be scanned/focused over the whole vertical height to get 3D model. Interferograms consist of fringes (light and dark bands) that represent the points of the same height. Achieved interferograms are digitally transformed into the topographic 3D model from which the surface height can be determined [32]. In this research the height of the island is determined by measuring the height difference between the middle and at the edge of the island. The middle and edge of the island are determined visually. Results show that the height of islands ranges from $0.1978 \mu \mathrm{m}$ to $1.0075 \mu \mathrm{m}$, as shown in Figure 7.
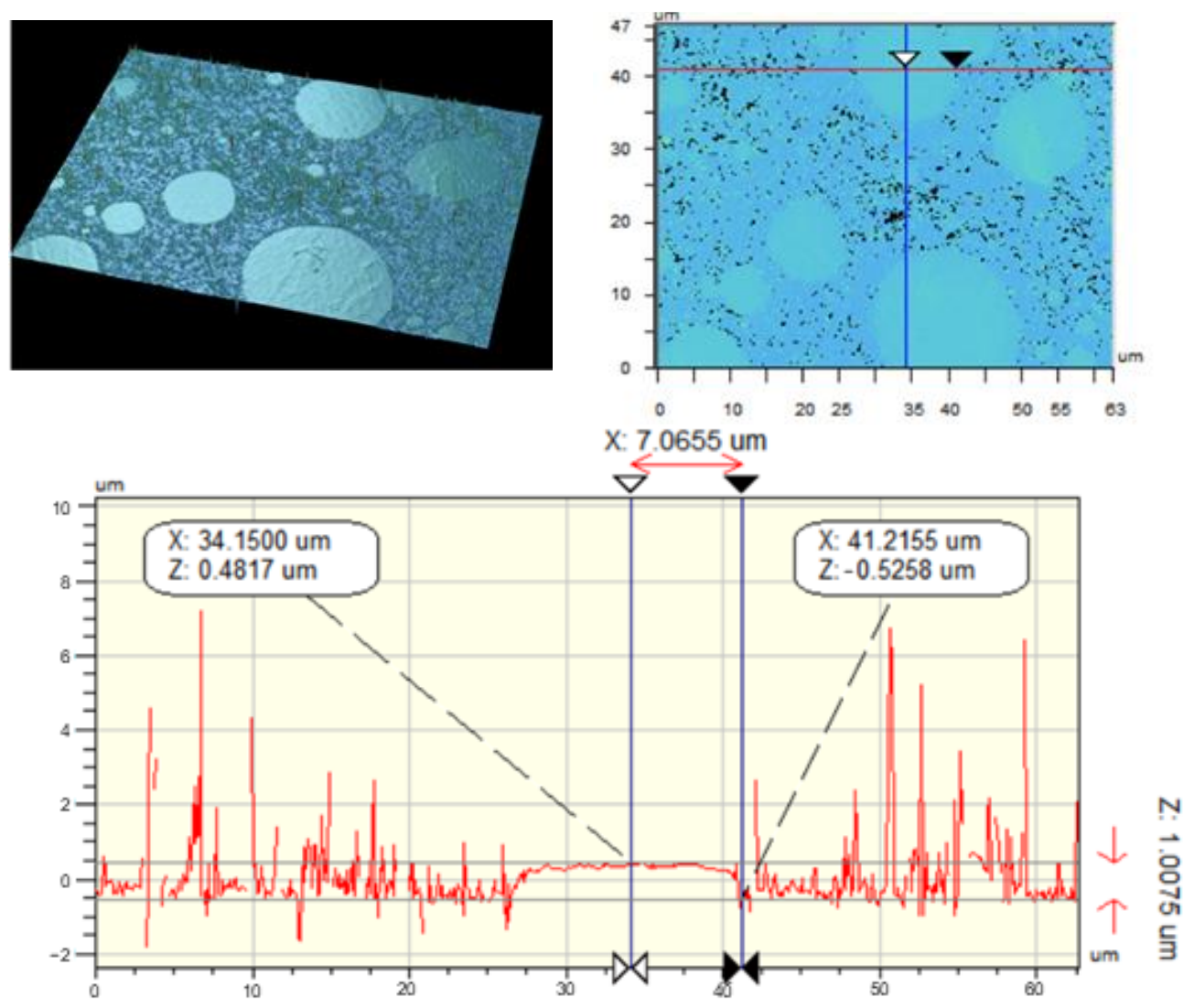

Figure 7. Results of the vertical scanning interferometry (VSI)-pictures of the surface and height profile of the sample PLA/PE-HD 80/20 E 4000 s + T 30 min.

Obtained results for PLA polymer blends do not deviate from previous studies where it has been revealed that the contact angles, that can be related to hydrophobicity, were achieved at the "island like" structures with the island height of $0.2 \mu \mathrm{m}$ [28], i.e., at the surface with the pillar structures up to $30 \mu \mathrm{m}$ high [33]. Furthermore, if the measured contact angles and measured heights of the island are shown on the same graph, the same trend is determined (Figure 8). Additionally, higher water contact angles were measured on the surfaces with higher islands. This confirms the conclusions of previous research that the hydrophobicity of the surface also depends on the height of the islands. 


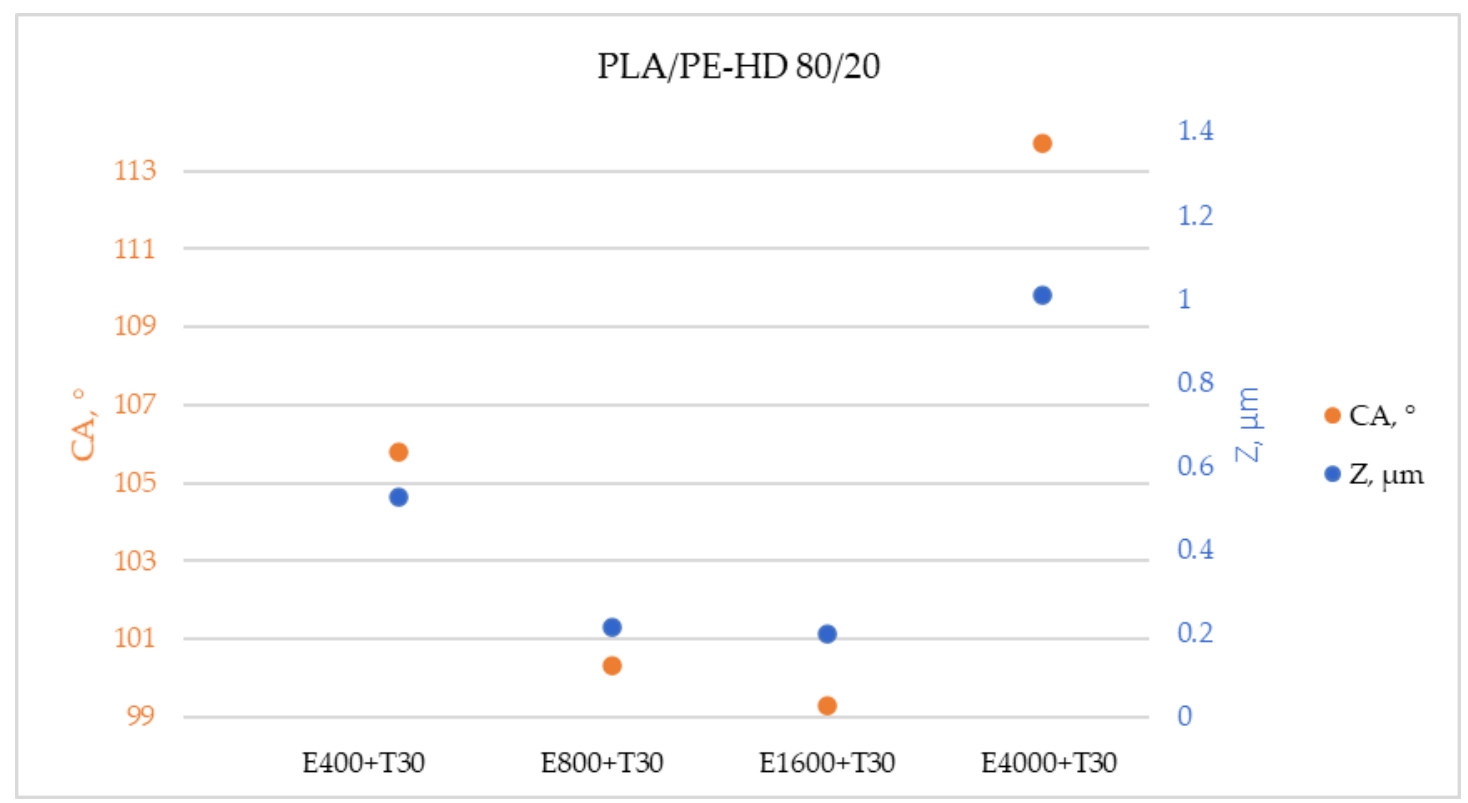

Figure 8. Results of the vertical scanning interferometry (VSI)-trend of contact angle and island height change in relation to applied treatment on PLA/PE-HD 80/20 (E-etching in $\mathrm{s}, \mathrm{T}-\mathrm{CF}_{\mathrm{x}}$ coating in min, CA-contact angle, Z-island height).

The results of contact angle measurements for ABS/PE-LD and ABS/PE-HD polymer blends are shown in Figures 9 and 10. All data can be found in Supplementary Materials-Table S2.

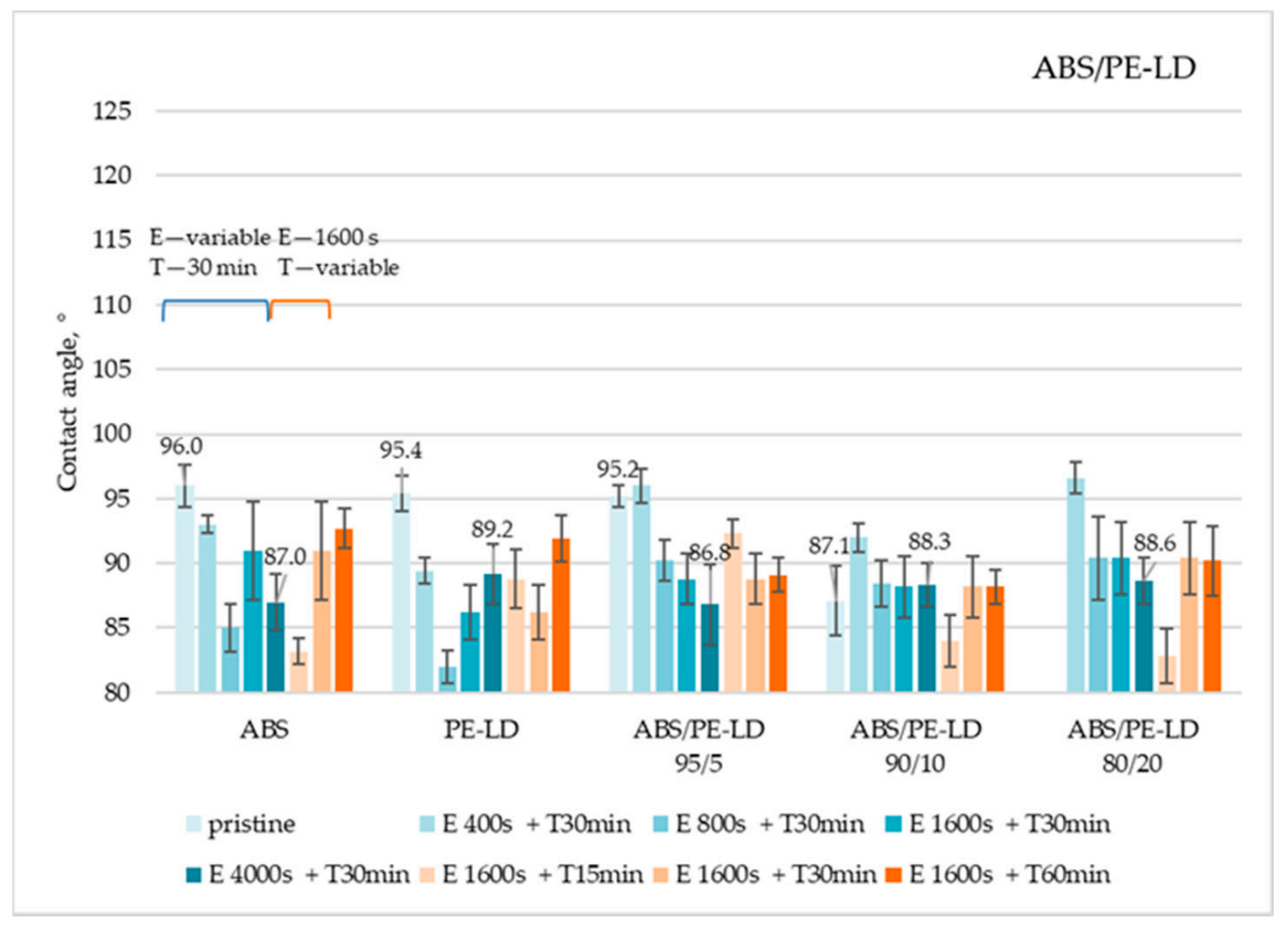

Figure 9. Water contact angles on ABS/PE-LD polymer blends treated under different etching and coating conditions (E-etching; $\mathrm{T}-\mathrm{CF}_{\mathrm{x}}$ coating). 


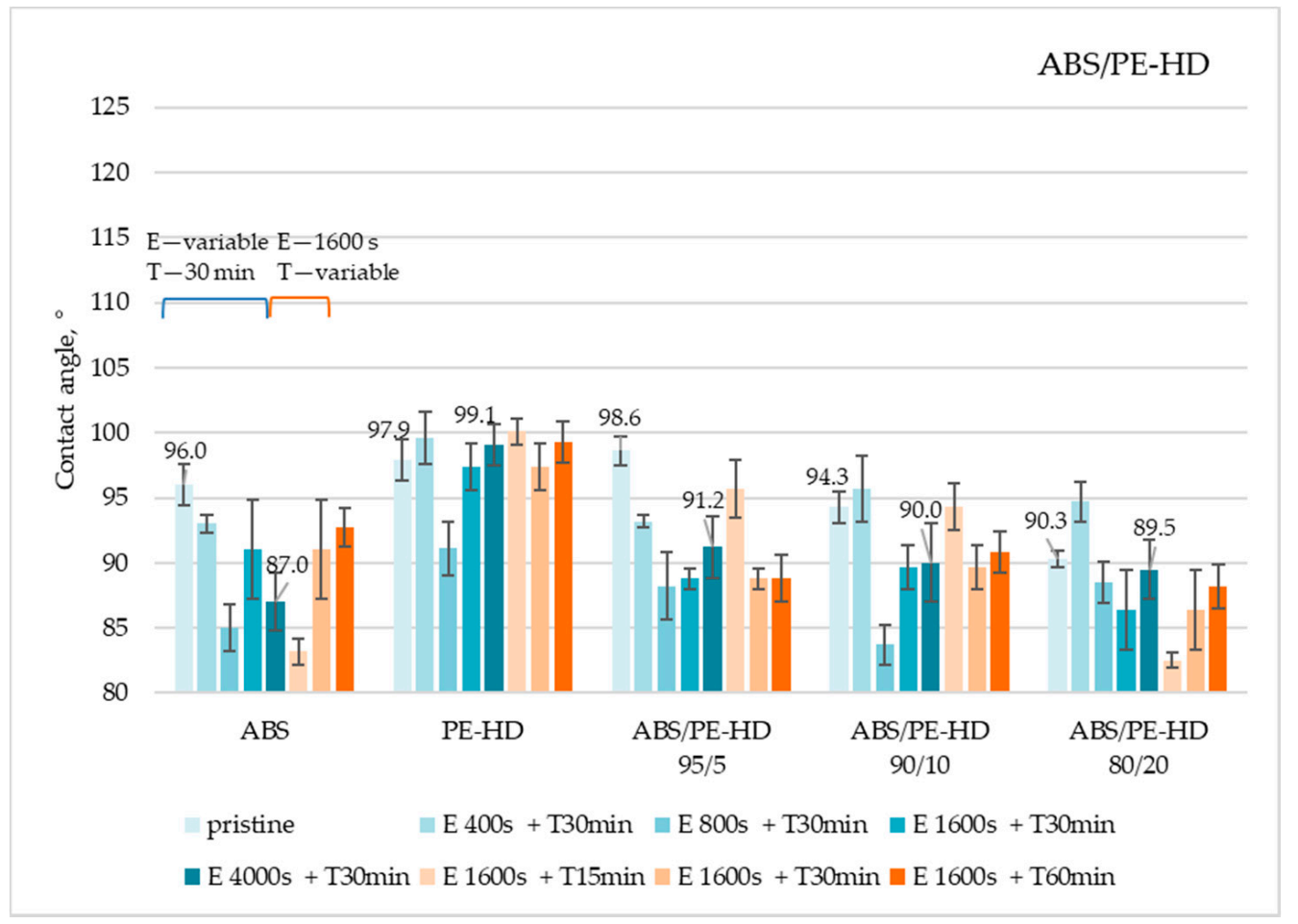

Figure 10. Water contact angles on ABS/PE-HD polymer blends treated under different etching and coating conditions (E-etching; $\mathrm{T}-\mathrm{CF}_{\mathrm{x}}$ coating).

Obtained results showed that, in principle, on all ABS/PE-LD (Figure 9) and ABS/PE-HD (Figure 10) polymer blends no significant increase in the contact angle is achieved by etching and $\mathrm{CF}_{\mathrm{x}}$ coating. Additionally, an increase in coating time has no impact on gaining a higher contact angle. This is also confirmed with the SEM micrographs of untreated and treated surfaces of ABS/PE-LD and ABS/PE-HD (Figures 11 and 12) where modification of surface roughness is not visible
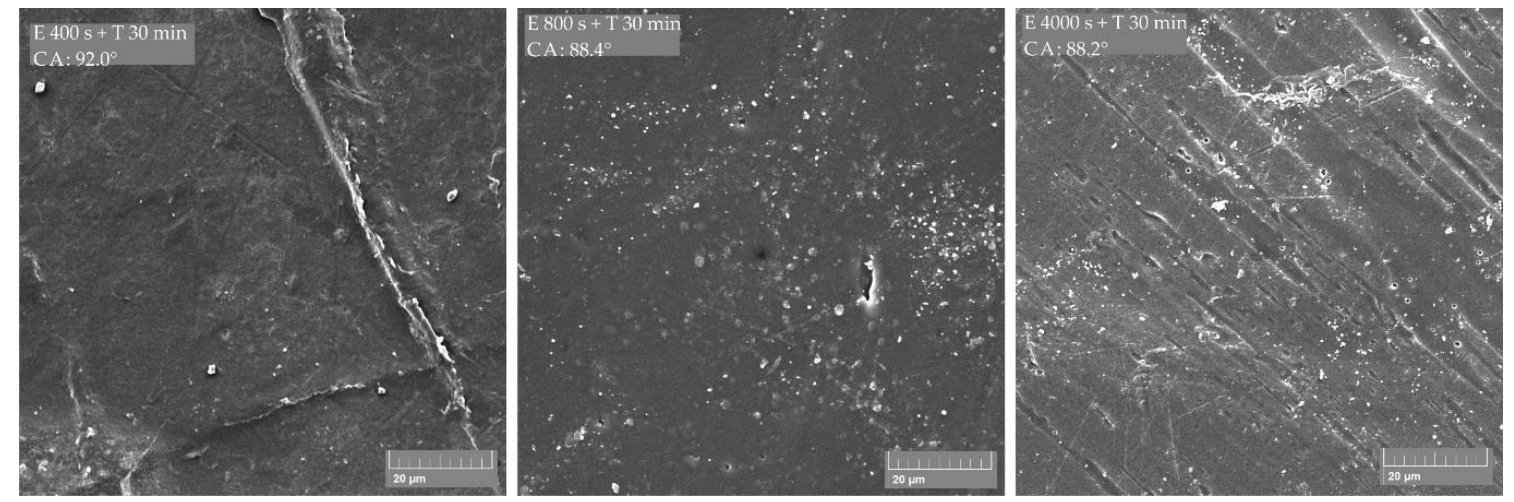

Figure 11. SEM micrographs of untreated ABS/PE-LD 90/10 polymer blend and treated by etching (E) and $\mathrm{CF}_{\mathrm{x}}$ coating $(\mathrm{T})$; measured contact angle is indicated as $\mathrm{CA}$.

In contrast to polymer blends with PLA, it is shown that etching and $\mathrm{CF}_{\mathrm{x}}$ coating could not significantly change the properties and morphology of the surface in polymer blends with ABS (Figures 11 and 12). No significant change is found on the surface nor the characteristic "island like" structures are created on the surface even though the existence of dispersed domains of PE-LD, as well as PE-HD, in the ABS matrix exists (Figure 13). 

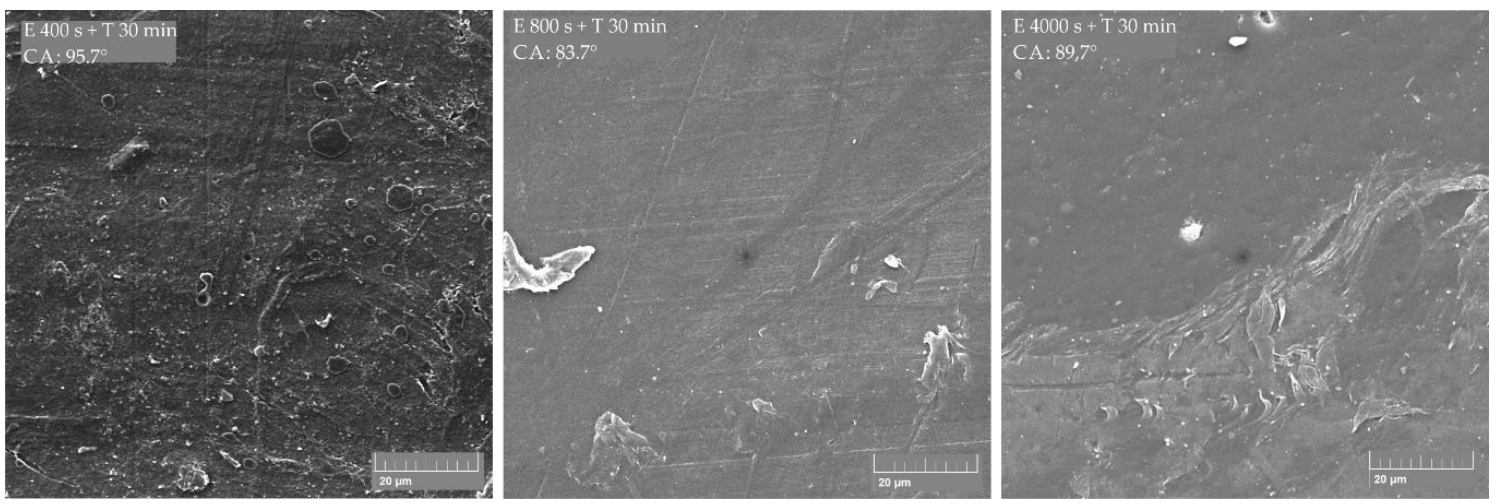

Figure 12. SEM micrographs of untreated ABS/PE-HD 90/10 polymer blend and treated by etching (E) and $\mathrm{CF}_{\mathrm{X}}$ coating $(\mathrm{T})$; measured contact angle is indicated as $\mathrm{CA}$.

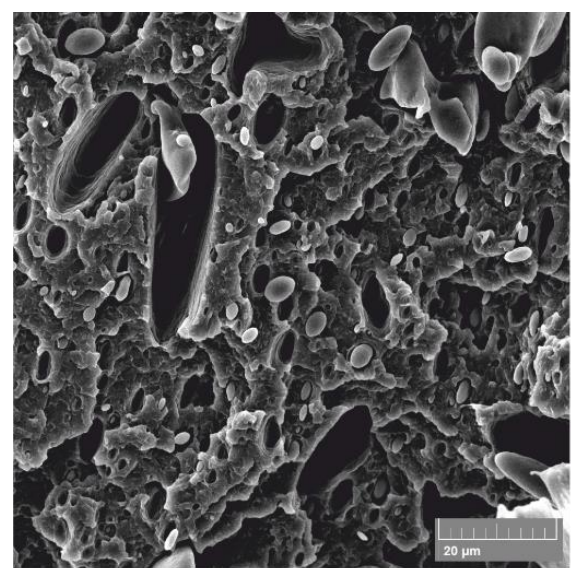

(a)

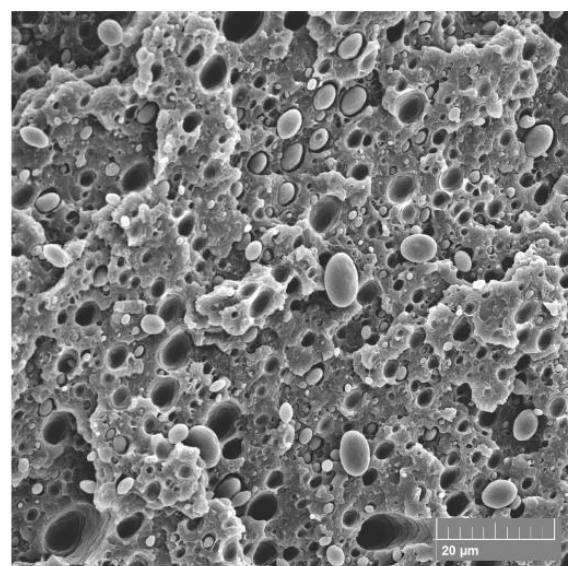

(b)

Figure 13. SEM micrographs on the fracture surface of the untreated samples; (a) ABS/PE-LD 90/10 and (b) ABS/PE-HD 90/10.

Since the treatment of samples with ABS was carried out in the same batch and at the same time as the samples with PLA (which showed a change in the surface morphology of polymer blend) it cannot be concluded that the treatment process was faulty or unsuccessful. Additionally, previous research has shown that surface roughness of both PE and ABS can be modified with argon plasma, i.e., argon ion beam [34,35]. The obtained results for morphology and contact angle of treated ABS/PE-LD and ABS/PE-HD samples may indicate that ABS and PE react equally to plasma, so the etching rate is the same in all areas on the surface, both on the ABS matrix and on the dispersed domain of PE [36], due to which there was no change at the surface structure, and consequently no increase in the contact angle. Additionally, the reason may be in the etching conditions-the strength of the applied plasma and the etching time. Previous studies have shown that the etching time may be insufficient to treat the surface [36] and that the plasma power and etching time exceed the value of critical power and critical processing time followed by a decrease in the total surface roughness [37]. However, to draw a firm conclusion further research is needed.

In order to prove the possibility of using the PLA/PE-HD 90/10 polymer blend for the manufacturing of microreactors using the 3D printing, a microreactor measuring $48 \mathrm{~mm} \times 14 \mathrm{~mm} \times 3 \mathrm{~mm}$ was produced (Figure 14). Since the microreactor is made of an opaque polymer blend it is not possible to see the microchannels inside the reactor when it is finished. In order to see the channels inside the reactor, a part of the microreactor with an open top surface was additionally 3D printed. 

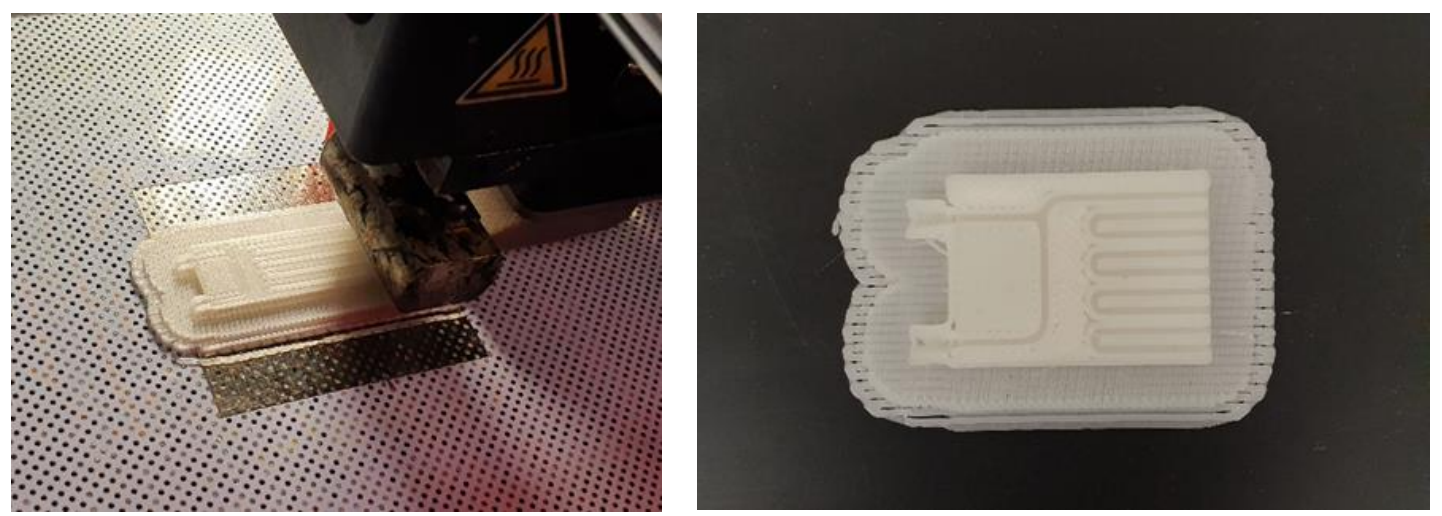

Figure 14. Production process of a microreactor produced by 3D printing and a part of a microreactor with visible microchannels.

\section{Conclusions}

In this research, it has been shown that the modification of the surface morphology of PLA polymer blends can be achieved by ICP etching and fluorocarbon coating. The treated surface of 90/10 PLA/PE-HD showed a contact angle of $121.6^{\circ}$, which is $36^{\circ}$ higher than the contact angle measured on the untreated surface. Surfaces that have achieved contact angles higher than $120^{\circ}$ have an "island like" surface morphology. The highest contact angle was achieved on a surface with the $4 \mu \mathrm{m}$ to $8 \mu \mathrm{m}$ wide islands, where the $6 \mu \mathrm{m}$ wide islands were the most common. Distance between islands ranged from $10 \mu \mathrm{m}$ to $20 \mu \mathrm{m}$. This surface structure was achieved by etching for $4000 \mathrm{~s}$ and $\mathrm{CF}_{\mathrm{X}}$ coating for $30 \mathrm{~min}$. Samples with higher islands showed higher contact angles, that confirmed that the hydrophobicity also depends on the height of the islands. Furthermore, it was found that etching time significantly impacts the contact angle values and surface morphology of the PLA polymer blends, while the $\mathrm{CF}_{\mathrm{x}}$ coating time has no significant impact on the surface properties.

Unlike the PLA polymer blends, it has been shown that ICP etching and fluorocarbon coating under the treatment conditions applied in this research cannot significantly change the surface of ABS polymer blends. Additionally, "island like" surface morphology cannot be produced on the ABS polymer blends surfaces under the applied treatment conditions.

Supplementary Materials: The following are available online at http://www.mdpi.com/1996-1944/13/23/5578/s1, Table S1: Water contact angles on PLA/PE-LD and PLA/PE-HD polymer blends treated under different etching conditions and different coating conditions (E-etching; T-CFx coating), Table S2: Water contact angles on ABS/PE-LD and ABS/PE-HD polymer blends treated under different etching conditions and different coating conditions (E-etching; T-CFx coating).

Author Contributions: Conceptualization, V.L.M. and D.V.; methodology, D.V.; software, C.G., M.T. and D.V.; validation, I.G.; formal analysis, V.L.M., C.G., M.T. and D.V.; investigation, V.L.M. and D.V.; resources, C.G., M.T. and D.V.; data curation, V.L.M.; writing-original draft preparation, V.L.M. and D.V.; writing-review and editing, I.G. and D.V.; visualization, V.L.M.; supervision, C.G., M.T. and D.V.; project administration, C.G., M.T. and D.V.; funding acquisition, I.G., C.G., M.T. and D.V. All authors have read and agreed to the published version of the manuscript.

Funding: This work has been supported by Croatian Science Foundation under the project entitled "Development of materials for 3D printing of microreactors" (UIP-2014-09-3154), by European Regional Development Fund under the project "Waste and Sun for photocatalytic degradation of micropollutants in water" (OS-Mi, KK.01.1.1.04.0006). This work has received the support of "Institut Pierre-Gilles de Gennes" (laboratoire d'excellence, "Investissements d'avenir" program ANR-10-IDEX-0001-02 PSL and ANR-10-LABX-31.), ANR-10-EQPX-34 (Equipex IPGG) and the Institut Carnot IPGG Microfluidique.

Conflicts of Interest: The authors declare no conflict of interest. The funders had no role in the design of the study; in the collection, analyses, or interpretation of data; in the writing of the manuscript, or in the decision to publish the results.

\section{References}

1. Wenzel, R.N. Surface Roughness and Contact Angle. J. Phys. Colloid Chem. 1949, 53, 1466-1467. [CrossRef] 
2. Cassie, A.B.D.; Baxter, S. Wettability of porous surfaces. Trans. Faraday Soc. 1944, 40, 546-551. [CrossRef]

3. Cassie, A.B.D. Contact angles. Discuss. Faraday Soc. 1948, 3, 11-16. [CrossRef]

4. McHale, G.; Shirtcliffe, N.J.; Newton, M.I. Super-hydrophobic and super-wetting surfaces: Analytical potential? Analyst 2004, 129, 284-287. [CrossRef]

5. Barthlott, W.; Neinhuis, C. Purity of the sacred lotus, or escape from contamination in biological surfaces. Planta 1997, 202, 1-8. [CrossRef]

6. Yao, M.; Deng, H.; Mai, F.; Wang, K.; Zhang, Q.; Chen, F.; Fu, Q. Modification of poly(lactic acid)/poly (propylene carbonate) blends through melt compounding with maleic anhydride. Express Polym. Lett. 2011, 5, 937-949. [CrossRef]

7. Tsuji, H.; Ikada, Y. Blends of isotactic and atactic poly(lactide)s: 2. Molecular-weight effects of atactic component on crystallization and morphology of equimolar blends from the melt. Polymer 1996, 37, 595-602. [CrossRef]

8. Ploypetchara, N.; Suppakul, P.; Atong, D.; Pechyen, C. Blend of Polypropylene/Poly(lactic acid) for Medical Packaging Application: Physicochemical, Thermal, Mechanical, and Barrier Properties. Energy Procedia 2014, 56, 201-210. [CrossRef]

9. Park, J.W.; Im, S.S.; Kim, S.H.; Kim, Y.H. Biodegradable polymer blends of poly(L-lactic acid) and gelatinized starch. Polym. Eng. Sci. 2000, 40, 2539-2550. [CrossRef]

10. Park, J.W.; Im, S.S. Miscibility and morphology in blends of poly(l-lactic acid) and poly(vinyl acetate-co-vinyl alcohol). Polymer 2003, 44, 4341-4354. [CrossRef]

11. Vazquez, Y.V.; Barbosa, S.E. Compatibilization of HIPS/ABS blends from WEEE by using Styrene-Butadiene Rubber (SBR). J. Environ. Manag. 2018, 217, 381-390. [CrossRef] [PubMed]

12. Cosas Fernandes, J.P.; Castro, L.D.C.; Mareau, V.H.; Pessan, L.A.; Gonon, L. New insights on the compatibilization of PA6/ABS blends: A co-localized AFM-Raman study. Polymer 2018, 146, 151-160. [CrossRef]

13. Rigoussen, A.; Verge, P.; Raquez, J.-M.; Habibi, Y.; Dubois, P. In-depth investigation on the effect and role of cardanol in the compatibilization of PLA/ABS immiscible blends by reactive extrusion. Eur. Polym. J. 2017, 93, 272-283. [CrossRef]

14. Hirayama, D.; Saron, C. Morphologic and mechanical properties of blends from recycled acrylonitrilebutadiene-styrene and high-impact polystyrene. Polymer 2018, 135, 271-278. [CrossRef]

15. Hoefnagels, H.F.; Wu, D.; de With, G.; Ming, W. Biomimetic Superhydrophobic and Highly Oleophobic Cotton Textiles. Langmuir 2007, 23, 13158-13163. [CrossRef] [PubMed]

16. Huang, F.L.; Wei, Q.F.; Xu, W.Z.; Li, Q. Preparation and characterizations of PTFE gradient nanostructure on silk fabric. Surf. Rev. Lett. 2007, 14, 547-551. [CrossRef]

17. Zhang, X.; Jin, M.; Liu, Z.; Tryk, D.A.; Nishimoto, S.; Murakami, T.; Fujishima, A. Superhydrophobic TiO 2 Surfaces: Preparation, Photocatalytic Wettability Conversion, and Superhydrophobic-Superhydrophilic Patterning. J. Phys. Chem. C 2007, 111, 14521-14529. [CrossRef]

18. Boscher, N.D.; Choquet, P.; Duday, D.; Verdier, S. Chemical compositions of organosilicon thin films deposited on aluminium foil by atmospheric pressure dielectric barrier discharge and their electrochemical behaviour. Surf. Coat. Technol. 2010, 205, 2438-2448. [CrossRef]

19. Hosono, E.; Fujihara, S.; Honma, I.; Zhou, H. Superhydrophobic Perpendicular Nanopin Film by the Bottom-Up Process. J. Am. Chem. Soc. 2005, 127, 13458-13459. [CrossRef]

20. Zhang, X.; Shi, F.; Yu, X.; Liu, H.; Fu, Y.; Wang, Z.; Jiang, L.; Li, X. Polyelectrolyte Multilayer as Matrix for Electrochemical Deposition of Gold Clusters: Toward Super-Hydrophobic Surface. J. Am. Chem. Soc. 2004, 126, 3064-3065. [CrossRef]

21. Buck, M.E.; Schwartz, S.C.; Lynn, D.M. Superhydrophobic Thin Films Fabricated by Reactive Layer-by-Layer Assembly of Azlactone-Functionalized Polymers. Chem. Mater. 2010, 22, 6319-6327. [CrossRef] [PubMed]

22. Ramaratnam, K.; Tsyalkovsky, V.; Klep, V.; Luzinov, I. Ultrahydrophobic textile surface via decorating fibers with monolayer of reactive nanoparticles and non-fluorinated polymer. Chem. Commun. 2007, 4510-4512. [CrossRef] [PubMed]

23. Zhang, X.; Kono, H.; Liu, Z.; Nishimoto, S.; Tryk, D.A.; Murakami, T.; Sakai, H.; Abe, M.; Fujishima, A. A transparent and photo-patternable superhydrophobic film. Chem. Commun. 2007, 4949-4951. [CrossRef] [PubMed] 
24. Jafari, R.; Asadollahi, S.; Farzaneh, M. Applications of Plasma Technology in Development of Superhydrophobic Surfaces. Plasma Chem. Plasma Process. 2013, 33, 177-200. [CrossRef]

25. Balu, B.; Breedveld, V.; Hess, D.W. Fabrication of "Roll-off" and "Sticky" Superhydrophobic Cellulose Surfaces via Plasma Processing. Langmuir 2008, 24, 4785-4790. [CrossRef]

26. Favia, P.; Cicala, G.; Milella, A.; Palumbo, F.; Rossini, P.; D'Agostino, R. Deposition of super-hydrophobic fluorocarbon coatings in modulated RF glow discharges. Surf. Coat. Technol. 2003, 169-170, 609-612. [CrossRef]

27. Hirotsu, T.; Castillo, M.; Nakayama, K.; Tsuruta, S.; Suzuki, H. Surface wetting phenomena of plasma polymer-coated sheets of poly(1-lactic acid)/poly(butylene succinate). Thin Solid Films 2007, 515, 4125-4129. [CrossRef]

28. Vrsaljko, D.; Grčić, I.; Guyon, C.; Schelcher, G.; Tatoulian, M. Designing Hydrophobicity of the PLA Polymer Blend Surfaces by ICP Etching. Plasma Process. Polym. 2016, 13, 869-878. [CrossRef]

29. Kato, K. Electron microscope studies on the etching of ABS mouldings for electroplating. Polymer 1968, 9, 419-424. [CrossRef]

30. de J. Santos, R.; Bruno, V.; Silva, M.T.M.B.; Nunes, R.C.R. An etching technique for morphological investigation of TPU/ABS blends by SEM. Polym. Test. 1993, 12, 393-400. [CrossRef]

31. Lovinčić Milovanović, V.; Hajdinjak, I.; Lovriša, I.; Vrsaljko, D. The influence of the dispersed phase on the morphology, mechanical and thermal properties of PLA/PE-LD and PLA/PE-HD polymer blends and their nanocomposites with TiO2 and CaCO3. Polym. Eng. Sci. 2019, 59, 1395-1408. [CrossRef]

32. Legutko, S.; Krolczyk, G.; Krolczyk, J. Quality Evaluation of Surface Layer in Highly Accurate Manufacturing. Manuf. Technol. 2014, 14, 50-56. [CrossRef]

33. Jung, Y.C.; Bhushan, B. Contact angle, adhesion and friction properties of micro-and nanopatterned polymers for superhydrophobicity. Nanotechnology 2006, 17, 4970-4980. [CrossRef]

34. Spyrides, S.M.M.; Alencastro, F.S.; Guimaraes, E.F.; Bastian, F.L.; Simao, R.A. Mechanism of oxygen and argon low pressure plasma etching on polyethylene (UHMWPE). Surf. Coat. Technol. 2019, 378, 124990. [CrossRef]

35. Ahmed, S.F.; Yi, J.W.; Moon, M.-W.; Jang, Y.-J.; Park, B.-H.; Lee, S.-H.; Lee, K.-R. The Morphology and Mechanical Properties of Polycarbonate/Acrylonitrile Butadiene Styrene Modified by Ar Ion Beam Irradiation. Plasma Process. Polym. 2009, 6, 860-865. [CrossRef]

36. Chapman, B. Glow Discharge Processes: Sputtering and Plasma Etching; John Wiley \& Sons: New York, NY, USA, 1980.

37. Palumbo, F.; Di Mundo, R.; Cappelluti, D.; D'Agostino, R. SuperHydrophobic and SuperHydrophilic Polycarbonate by Tailoring Chemistry and Nano-texture with Plasma Processing. Plasma Process. Polym. 2011, 8, 118-126. [CrossRef]

Publisher's Note: MDPI stays neutral with regard to jurisdictional claims in published maps and institutional affiliations.

(C) 2020 by the authors. Licensee MDPI, Basel, Switzerland. This article is an open access article distributed under the terms and conditions of the Creative Commons Attribution (CC BY) license (http://creativecommons.org/licenses/by/4.0/). 